\title{
Avraham Faust, Hayah Katz, Pirchia Eyall. "Late Persian-Early Hellenistic Remains at Tel 'Eton”
}

\section{Astrid Nunn}

\section{(2) OpenEdition}

1 Journals

\section{Édition électronique}

URL : http://journals.openedition.org/abstractairanica/45390

DOI : 10.4000/abstractairanica.45390

ISBN : 1961-960X

ISSN : 1961-960X

Éditeur :

CNRS (UMR 7528 Mondes iraniens et indiens), Éditions de l'IFRI

Référence électronique

Astrid Nunn, « Avraham Faust, Hayah Katz, Pirchia Eyall. "Late Persian-Early Hellenistic Remains at Tel "Eton" », Abstracta Iranica [En ligne], Volume 37-38-39 | 2018, document 39, mis en ligne le 30 décembre 2018, consulté le 27 septembre 2020. URL : http://journals.openedition.org/ abstractairanica/45390 ; DOI : https://doi.org/10.4000/abstractairanica.45390

Ce document a été généré automatiquement le 27 septembre 2020.

Tous droits réservés 


\title{
Avraham Faust, Hayah Katz, Pirchia Eyall. "Late Persian-Early Hellenistic Remains at Tel 'Eton"
}

\author{
Astrid Nunn
}

\section{RÉFÉRENCE}

Avraham Faust, Hayah Katz, Pirchia Eyall. "Late Persian-Early Hellenistic Remains at Tel "Eton", Tel Aviv (Journal of the Institute of Archaeology of Tel Aviv University) 42/1, 2015, p. 103-126.

Le site de Tel 'Eton, localisé dans la plaine de la Shéphélah à $3 \mathrm{~km}$ au nord de Tell Beit Mirsim, a déjà été mentionné dans AI 34-36, nº 62 (FAUST, Avraham ; KATZ, Hayah. "Survey, Shovel Tests and Excavations at Tel "Eton: On Methodology and Site History ». Tel Aviv 39, 2012, p. 158-185). C'est la raison pour laquelle le site est recensé ici, même si sa couche achéménide remonte à la toute fin de cette époque. Le site a été habité du IV ème au début du III ème s. av. n. è. et comprenait alors un fort entouré d'un village. Les A. présentent ici l'architecture et la céramique et discutent des raisons aussi bien de sa fondation après un hiatus de 300-350 ans que de son abandon.

\section{AUTEURS}

ASTRID NUNN

Université de Munich 